\title{
PERFIL DE CONSUMO E DO CONSUMIDOR DE PEIXE DO MUNICÍPIO DE SINOP, MATO GROSSO
}

\author{
Stephane Vasconcelos Leandro'; Sullyvan Silva Oliveira²; Paula Sueli Andrade Moreira ${ }^{3}$; Fabrizia Sayuri \\ Otani ${ }^{4}$. \\ ${ }^{1}$ Universidade Federal de Mato Grosso, Sinop, Mato Grosso, Brasil, phane.ster@gmail.com \\ 2Universidade Federal do Oeste do Pará, Santarém, Pará, Brasil, sullyvanoliveira23@gmail.com \\ 3Universidade Federal de Mato Grosso, Sinop, Mato Grosso, Brasil, paula_moreira@ufmt.br \\ ^universidade Federal do Oeste do Pará, Santarém, Pará, Brasil, fabrizia_otani@yahoo.com.br
}

RESUMO: Este trabalho foi efetuado no perímetro urbano do município de Sinop, no norte do estado brasileiro de Mato Grosso. O objetivo desse estudo foi caracterizar o perfil de consumo e consumidor de peixe, que reside no município de Sinop, Mato Grosso. Foram aplicados 448 questionários em locais de intenso fluxo diário de pessoas. Utilizou-se um questionário constituído de 37 questões descritivas, que abrangeu os seguintes pontos de interesse: características socioeconômicas do entrevistado, quantificação do consumo, determinantes do consumo, preferências de consumo e conhecimento sobre a cadeia de produção. A coleta de dados foi realizada no período de 06 fevereiro a 13 de março de 2017. O perfil do consumidor de peixe de Sinop foi formado pelos fatores sexo, idade, estado brasileiro de origem, escolaridade e renda familiar. De modo geral os resultados indicaram que 0 percentual dos entrevistados que afirmaram consumir peixe foi maior que $90 \%$. Apesar do município estar localizado em uma região de grande potencial para a produção de peixe a frequência e quantidade de consumo são baixas. O consumo de peixe em Sinop é influenciado diretamente pela renda familiar dos consumidores, influência cultural e hábitos alimentares dos colonizadores do município. As espécies preferidas são a matrinxã e o tambaqui, seguidos do Pintado da Amazônia. A qualidade e o preço são fatores importantes para o consumo. O consumidor sugere principalmente a diminuição do preço do peixe e a melhoria da qualidade e higiene do produto e locais de venda.

PALAVRAS-CHAVE: Mercado, Pescado, Qualidade.

\section{CONSUMPTION AND FISH CONSUMER PROFILE OF THE MUNICIPALITY OF SINOP, MATO GROSSO}

ABSTRACT: This work was carried out in the urban perimeter of the Sinop City, in the north of Brazil in Mato Grosso state. The objective of this study was to characterize the fish consumption and consumer profile, which resides in Sinop city, Mato Grosso. About 448 questionnaires were applied in places with intense daily flow of people. A 
questionnaire consisted of 37 descriptive questions, covering the following points of interest: socioeconomic characteristics of the interviewee, quantification of consumption, determinants of consumption, preferences of consumption and knowledge about the production chain. Data collection was carried out from 06 February to 13 March 2017. The fish consumer profile of Sinop was formed by the factors such as: sex, age, Brazilian state of origin, schooling and family income. In general, the results indicated that the percentage of respondents who reported consuming fish was greater than $90 \%$. Although the city is located in a region with great potential for fish production, the frequency and amount of consumption are low. The consumption of fish in Sinop is directly influenced by the family income of the consumers, cultural influence and eating habits of the colonizers of the city. The preferred species are matrinxã and tambaqui, followed by Pintado da Amazônia. Quality and price are important factors for consumption. The consumer mainly suggests the reduction of the fish' price e and the improvement of the product's quality and hygiene and places of fish's sale.

KEYWORDS: Fish, Market, Quality.

\section{CONSUMO Y PESCADO PERFIL DEL CONSUMIDOR DEL MUNICIPIO DE SINOP, MATO GROSSO}

RESUMEN: Este trabajo fue efectuado en el perímetro urbano del municipio de Sinop, en el norte del estado brasileño de Mato Grosso. El objetivo de este estudio fue caracterizar el perfil de consumo y consumidor de pescado, que reside en el municipio de Sinop, Mato Grosso. Se aplicaron 448 cuestionarios en lugares de intenso flujo diario de personas. Se utilizó un cuestionario constituido de 37 cuestiones descriptivas, que abarcó los siguientes puntos de interés: características socioeconómicas del entrevistado, cuantificación del consumo, determinantes del consumo, preferencias de consumo y conocimiento sobre la cadena de producción. La recolección de datos fue realizada en el período del 6 de febrero al 13 de marzo de 2017. El perfil del consumidor de pescado de Sinop fue formado por los factores sexo, edad, estado brasileño de origen, escolaridad e ingreso familiar. En general, los resultados indicaron que el porcentaje de los entrevistados que afirmaron consumir pescado fue mayor que el 90\%. Aunque el municipio está situado en una región de gran potencial para la producción de pescado, la frecuencia y la cantidad de consumo son bajas. El consumo de pescado en Sinop es influenciado directamente por la renta familiar de los consumidores, influencia cultural y hábitos alimentarios de los colonizadores del municipio. Las especies preferidas son la matrinxã y el tambaqui, seguidos del Pintado de la Amazonia. La calidad y el precio son factores importantes para el consumo. El 
consumidor sugiere principalmente la disminución del precio del pescado y la mejora de la calidad e higiene del producto y locales de venta.

PALABRAS CLAVE: Calidad, Mercado, Pescado.

\section{INTRODUÇÃO}

A população mundial segundo a Organização das Nações Unidas - ONU - foi de 7,2 bilhões de pessoas no ano de 2013 (ONU, 2013). A medida que ocorre o aumento populacional cresce a demanda por alimentos, e o consumidor tem se tornado cada vez mais exigente, por isso há uma necessidade de suprir também a demanda por alimentos mais saudáveis (BRABO et al., 2016).

A produção mundial de pescado também está em constante crescimento. O setor da pesca e aquicultura, é fonte de renda para milhões de pessoas no mundo, em que se estima que a pesca e a aquicultura garantam a subsistência de 10 a 12\% da população mundial. Além disso, o pescado desempenha papel fundamental na segurança alimentar. $\bigcirc$ consumo per capita mundial de peixe aumentou de uma média de 9,9 Kg na década de 1960 para 17,0 Kg em 2000, e saltou para 18,9 Kg em 2010, isso pode ser resultado da combinação do crescimento populacional, rendimento e urbanização inter-relacionados à forte expansão da produção e modernos canais de distribuição. Há diferenças no padrão de consumo per capita entre e dentro dos diferentes países, em termos de quantidades e variedades. Essas diferenças estão relacionadas a disponibilidade e custo do peixe e alimentos alternativos, à renda, fatores socioeconômicos e culturais, tradições alimentares, gostos, demanda, estações, preços, infraestrutura, saúde e marketing. Esse consumo entre países varia de $1 \mathrm{Kg} \mathrm{a} 100 \mathrm{Kg}$, sendo geralmente mais elevado em países de zonas costeiras ou áreas de águas continentais (FAO, 2014).

O Brasil encontra-se em $11^{a}$ posição no ranking mundial de produção de peixes, soma da produção de peixes 
advindos da maricultura e águas continentais, num total de 611.343 toneladas. Por apresentar um grande potencial para a produção aquícola, o Brasil tem várias vantagens como possuir uma costa litorânea de 8,4 mil quilômetros, 5,5 milhões de hectares de reservatórios de água doce, além de um clima favorável, terras disponíveis, mão de obra barata e crescente mercado interno (PINHEIRO et al., 2014).

Porém, segundo o Ministério da Pesca e Aquicultura (MPA), o consumo per capita brasileiro de pescado em 2011 foi de 11,17 Kg (SEBRAE, 2015). No Brasil o pescado ocupa a quarta posição no consumo de proteínas animal, o que revela que uma parcela significativa dos brasileiros não possui o hábito de consumir peixe (SONODA; SHIROTA, 2012). A produção brasileira de pescado em 2013 foi de 1.241.807 toneladas de pescado, com produção por região de 140.748 toneladas no Nordeste, seguida pela região Sul com 107.448 toneladas, Centro-Oeste, com 105.010 toneladas, região Norte com 73.009 toneladas e por fim a região Sudeste com 50.297 toneladas (MPA, 2015).

A piscicultura de água doce está difundida em todo o Brasil, e os principais produtores estão na região Centro-Oeste, especialmente no estado do Mato Grosso, e na região Norte com destaque para os estados de Rondônia, Tocantins, Roraima, Amazonas, Acre e Pará (IBGE, 2015).

O estado do Mato Grosso apresenta grande potencial para a piscicultura por ser um dos lugares com maior volume de água doce no mundo, os rios do Estado estão divididos em três bacias hidrográficas mais importantes do Brasil: Bacia Amazônica, Bacia Platina e Bacia do Tocantins, além disso apresenta alta disponibilidade de produtos para a indústria de ração, clima favorável e alta demanda de consumo tanto dentro como fora do estado. Só em 2011 o estado produziu cerca de 49 mil toneladas de peixes cultivados em água doce, sendo o terceiro maior produtor nacional e o maior produtor na região Centro Oeste (FAMATO, 2014). 
Dentro do cenário de produção de proteína animal, os peixes são uma fonte valiosa pois uma porção de $150 \mathrm{~g}$ de peixe fornece de $50 \%$ a $60 \%$ das necessidades diárias da proteína, em termos de caloria sua contribuição alimentar é bem baixa com apenas 33 calorias per capita, além disso o peixe possui baixo teor de gorduras saturadas, colesterol e carboidratos, é ainda fonte de proteínas, ácidos graxos essenciais e micronutrientes (FAO, 2014).

A cidade de Sinop localizada ao Norte do Mato Grosso é um dos 141 municípios do estado. A cidade é resultado da política de ocupação da Amazônia Legal Brasileira, desenvolvida pelo Governo Federal na década de 1970. A fundação da cidade ocorreu em 1974, após a chegada das famílias pioneiras, que na maioria partiram dos Estados do Paraná, Santa Catarina e Rio Grande do Sul (IBGE, 2015). Grande parte dos moradores de Sinop são de outros municípios e estados, principalmente da região sul do Brasil, que em busca de melhores oportunidades de trabalho, estudo e qualidade de vida migraram para o município (ROMANCINI, 2009).

As escolhas alimentares determinam o consumo alimentar dos indivíduos, e isto constitui um processo complexo pois depende de vários fatores como a região geográfica, classe-econômica, questões culturais, história individual, personalidade e outros aspectos próprios de cada consumidor. $\bigcirc$ ato de se alimentar se desenvolve ainda de acordo com regras impostas pela sociedade, meio ambiente, e valores do grupo social no qual o indivíduo está inserido (ESTIMA et al., 2009).

Para se conhecer o mercado de um produto é preciso primeiramente analisar o perfil do consumidor, o meio social em que está inserido, o destino, a finalidade com que ele faz posse do produto, a quantidade e a frequência que faz uso deste além de suas preferências, entre outras finalidades (MCCARTHY; PERREAULT, 1997). Por isso a importância de se realizar um diagnóstico sobre consumo de peixe no município de Sinop, a fim de propor 
alternativas que melhorem a demanda pelo peixe e seus derivados.

Portanto esse trabalho visa caracterizar o perfil de consumo e dos consumidores de peixe residentes no município de Sinop, Mato Grosso, analisando se os habitantes do município consomem ou não peixe e quais os indicadores do consumo, com que frequência e quantidade ocorre o consumo de peixe, quais os fatores que influenciam na decisão de escolha, se esse consumidor gostaria de consumir mais peixe e o porquê, entre outros aspectos.

\section{MATERIAL E MÉTODOS}

Este trabalho foi efetuado no perímetro urbano do município de Sinop, ao norte do estado brasileiro de Mato Grosso, localizado às margens da BR 163 com coordenadas geográficas de latitude $11^{\circ} 86^{\prime} \mathrm{S}$ e longitude 55 50' W (TEIXEIRA, 2006).

O município de Sinop, teve sua origem no Núcleo de Colonização Celeste, de Jorge Martins Phillip, com área inicial de 198 mil hectares de terras destinadas à colonização. Em 1971 Ênio Pipino, que representava a Sociedade Imobiliária Noroeste do Paraná SINOP, adquiriu as terras de Phillip, e em 14 de setembro de 1974 fundou a cidade que recebeu por nome a sigla da firma (IBGE, 2013).

De acordo com o censo realizado pelo IBGE em 2010, a população de Sinop é estimada em 113.099 pessoas, e conta com uma área de cerca de 3.942,229 km2, pertencente ao Bioma da Amazônia na região Centro-Oeste (IBGE, 2011).

A elaboração do questionário foi baseada em diversos estudos publicados sobre o consumo de pescado e carnes no Brasil, e que destacaram como fatores determinantes do consumo, o preço, a higiene, a renda, os costumes regionais, as embalagens, o sabor, a maciez, a idade, o sexo, os locais de venda e outros fatores (MAIA, 2012; SILVEIRA et al., 2012).

O questionário foi elaborado em novembro de 2016 baseado nos seguintes pressupostos: o que leva ou 
impede o consumo de pescado no município; a forma que esse consumidor prefere o peixe; o preço; a qualidade; os pontos de venda; conhecimento sobre a origem do peixe que consomem; se notam diferença no sabor entre outros motivos, a fim de descobrir se a comunidade pesquisada de Sinop consome essa proteína e se os pontos de venda atendem as expectativas do consumidor.

A validação do questionário ocorreu em dezembro de 2016, com a aplicação de um teste com 20 indivíduos, onde utilizou-se um questionário semiestruturado de múltipla escolha, contendo trinta e sete itens que visaram traçar o perfil de consumo e consumidor de peixe em Sinop, a partir de dados socioeconômicos, frequência, hábito e preferência de consumo, espécies preferidas, avaliação da qualidade dos locais de aquisição e da própria proteína em questão além de influências no consumo de peixe.

O questionário definitivo ficou constituído de 37 questões descritivas, sendo trinta e três de múltipla escolha, e quatro questões abertas. As questões foram elaboradas com base em 5 áreas de interesse:

a) Características socioeconômicas do entrevistado: compreendida das cinco primeiras questões do questionário, onde os itens apontados foram sexo, idade, estado brasileiro de origem, escolaridade e renda.

b) Quantificação do consumo: neste item foi considerado se o indivíduo consome ou não peixe, a frequência e quantidade mensal em quilogramas que consome e se este gostaria de consumir mais ou não.

c) Determinantes do consumo: este item indicou os fatores que influenciam na aceitação ou não do peixe, como sabor, preço, valor nutricional, tipo de carne, presença de espinhos, qualidade, cheiro, preparo da carne, embalagens, aparência, procedência, benefícios a saúde, entre outros.

d) Preferências de consumo: este item abordou locais e ocasiões em que o consumidor prefere realizar o consumo de peixe, se prefere peixe 
marinho, de água doce ou de ambos ambientes, ou ainda peixe cultivado ou de rio. Se prefere peixe de escamas ou pele e quais as espécies preferidas. Locais onde gostaria de adquirir o pescado e quais as formas que prefere adquirir e preparar o produto.

e) Conhecimento sobre a cadeia de produção: se conhece a origem do peixe que compra, se já comeu peixe cultivado e se nota diferença entre este e o advindo da pesca extrativista.

A coleta de dados foi realizada no período de 06 fevereiro a 13 de março de 2017. Foram aplicados 448 questionários em locais de intenso fluxo diário de pessoas, em dias comerciais, de diversos bairros da área urbana do município, abrangendo os mais populosos e com maior circulação de pessoas, devido à presença de instituições de ensino, comércio e lazer.

Para o cálculo do número de entrevistados, utilizou-se fórmula de Amostragem Aleatória Simples (RYAN, 2012), considerando a população do município de Sinop de 113.099 pessoas, com intervalo de 95\% de confiança e erro padrão de 5\%.

Após as aplicações, os dados obtidos dos questionários respondidos válidos, foram digitados em planilha eletrônica do software de edição de planilha eletrônica Microsoft Office Excel $2013{ }^{\circledR}$, onde as respostas dos indivíduos foram dispostas em linhas e as questões em colunas, sendo uma coluna para cada questão.

Os dados foram submetidos a uma análise descritiva, onde observou-se a média e frequência das observações, e transformados em porcentagens pelo software de edição de planilha eletrônica Microsoft Office Excel $2013^{\circledR}$. A partir dos resultados da análise, gráficos foram gerados para facilitar a leitura, interpretação e discussão dos resultados.

\section{RESULTADOS E DISCUSSÃO}

O perfil de consumo e do consumo de pescado no município de Sinop, Mato Grosso, foi obtido com a aplicação de questionário e formado pelos seguintes fatores: sexo, idade, estado 
brasileiro de origem, escolaridade e renda familiar.

Dos 448 indivíduos que aceitaram participar da pesquisa, 434 indivíduos responderam aos questionários e constatou-se que destes 39,30\% eram do sexo masculino e $60,70 \%$ do sexo feminino (Tabela 1). A idade dos entrevistados era igual ou superior a 14 anos, onde a média da amostra entrevistada foi de 19 anos, sendo que o entrevistado mais novo possuía 14 anos e o mais velho 71 anos. Dos entrevistados 60,83\% são de origem do Mato Grosso, e os demais de outros estados. Quanto a escolaridade cerca de 39,63\% possuem ensino médio incompleto, 16,13\% médio completo e $22,12 \%$ ensino superior incompleto. A renda geralmente é de 1 a 5 saláriosmínimos, e dos respondentes 92,40\% afirmaram consumir peixe.

No que se refere ao consumo dentro das classes de sexo dos entrevistados, 91,95\% das mulheres consomem peixe e 8,05\% não consomem, já dos homens
92,90\% são consumidores de peixe e 7,10\% não. Esses dados mostram que não há diferença significativa entre as respostas ligadas a classe sexo. Tais resultados corroboram com o estudo realizado por Vasconcellos (2010), que verificou que não houve associação significativa para o consumo em relação ao sexo no município de Santo André, São Paulo, sendo que $71,1 \%$ das mulheres consomem peixe em confronto com 79,1\% dos homens.

A frequência de consumo pode ser influenciada por diversos fatores, como preço sabor, região geográfica, questões culturais e até mesmo questões socioeconômicas como a renda. Um importante fator em relação ao baixo consumo de pescado neste município está relacionado a cultura da comunidade, influenciada pelos seus colonizadores que são originários da região Sul do país, onde a principal fonte de proteína é carne bovina, aves e suínos. 
Tabela 1. Caracterização sócio demográfica, sexo, estado de origem, escolaridade, renda e consumo de peixe em porcentagem $(\%)(n=434)$.

\begin{tabular}{|c|c|c|c|}
\hline \multirow{2}{*}{\multicolumn{2}{|c|}{ Sexo }} & Masculino & 39,30 \\
\hline & & Feminino & 60,70 \\
\hline \multirow{20}{*}{\multicolumn{2}{|c|}{$\begin{array}{l}\text { Estado Brasileiro de } \\
\text { Origem }\end{array}$}} & Acre & 0,69 \\
\hline & & Alagoas & 0,23 \\
\hline & & Amazonas & 0,46 \\
\hline & & Bahia & 0,23 \\
\hline & & Distrito Federal & 0,23 \\
\hline & & Goiás & 1,61 \\
\hline & & Maranhão & 1,61 \\
\hline & & Minas Gerais & 1,15 \\
\hline & & Mato Grosso do Sul & 3,00 \\
\hline & & Mato Grosso & 60,83 \\
\hline & & Pará & 5,07 \\
\hline & & Paraíba & 0,46 \\
\hline & & Paraná & 6,91 \\
\hline & & Pernambuco & 0,46 \\
\hline & & Rio Grande do Sul & 2,76 \\
\hline & & Rio de Janeiro & 0,46 \\
\hline & & Roraima & 3,46 \\
\hline & & Santa Catarina & 2,76 \\
\hline & & São Paulo & 3,46 \\
\hline & & Não respondeu & 4,15 \\
\hline \multirow{8}{*}{\multicolumn{2}{|c|}{ Escolaridade }} & Analfabeto & 0,23 \\
\hline & & Fundamental incompleto & 1,61 \\
\hline & & Fundamental completo & 8,53 \\
\hline & & Médio incompleto & 39,63 \\
\hline & & Médio completo & 16,13 \\
\hline & & Superior incompleto & 22,12 \\
\hline & & Superior completo & 10,14 \\
\hline & & Não respondeu & 1,61 \\
\hline \multirow{7}{*}{\multicolumn{2}{|c|}{ Renda }} & Menos de 1 salário & 4,61 \\
\hline & & 1 a 2 salários & 25,81 \\
\hline & & 2 a 3 salários & 23,73 \\
\hline & & 3 a 5 salários & 22,35 \\
\hline & & Mais de 5 salários & 12,67 \\
\hline & & Outros & 7,37 \\
\hline & & Não respondeu & 3,46 \\
\hline \multirow{2}{*}{\multicolumn{2}{|c|}{ Consome peixe }} & $\operatorname{sim}$ & 92,4 \\
\hline & & Não & 7,6 \\
\hline
\end{tabular}


Neste estudo verificou-se a frequência de consumo pela renda familiar dos indivíduos, onde os indivíduos com renda nas faixas: inferior a um salário (1,84\%), de 1 a 2 salários (13,12\%), de 2 a 3 salários (11,02\%) e de 3 a 5 salários (6,30\%), consomem raramente. Da frequência total de consumo, entre os entrevistados, os que possuem renda acima de 5 salários consomem peixe pelo menos uma $(3,15 \%)$ ou mais de uma vez por mês (3,15\%). Essa diferença pode estar relacionada ao maior poder aquisitivo desses últimos consumidores em relação aos demais. Tem-se uma amostra de consumidores em que mais de $90 \%$ consomem peixe, porém esse consumo é baixo, visto que a maioria o realiza raramente $(37,53 \%)$, ou de uma a mais de uma vez no mês (35,70\%).

Ao perguntar se o consumidor de peixe em Sinop gostaria de consumir peixe com maior frequência cerca de $69,5 \%$ responderam que "Sim", consumiriam mais. Dados apresentados na Figura 1, mostram que somente os indivíduos com renda inferior a 1 salário em sua maioria responderam não ter interesse no aumento desse consumo, ao contrário das demais classes que afirmaram que gostariam de consumir mais carne de peixe e seus derivados.

Araújo et al. (2015), verificaram que $58,10 \%$ dos consumidores de peixe frequentadores da feira livre de Porto Real do Colégio em Alagoas gostariam de aumentar o consumo de peixe.

O consumidor de peixe de Sinop, com base na amostra de dados coletados, consome de 1 a 2 quilogramas de peixe por mês (81,33\%), ao passo que uma minoria (18,67\%) consome de 3 a 4 quilogramas.

Verificou-se ainda que somente os que responderam consumir peixe todos os dias têm maior frequência percentual de consumo em Kg/mês de peixe, ou seja, cerca de $75 \%$ desses consumidores consomem de 3 a 4 quilogramas de peixe no mês, enquanto aqueles que consomem com menor frequência consomem de 1 a 2 quilogramas mensais de peixe (Figura 2). 
Figura 1. Resposta por classe de renda familiar dos entrevistados sobre o interesse em aumentar ou não o consumo peixe.

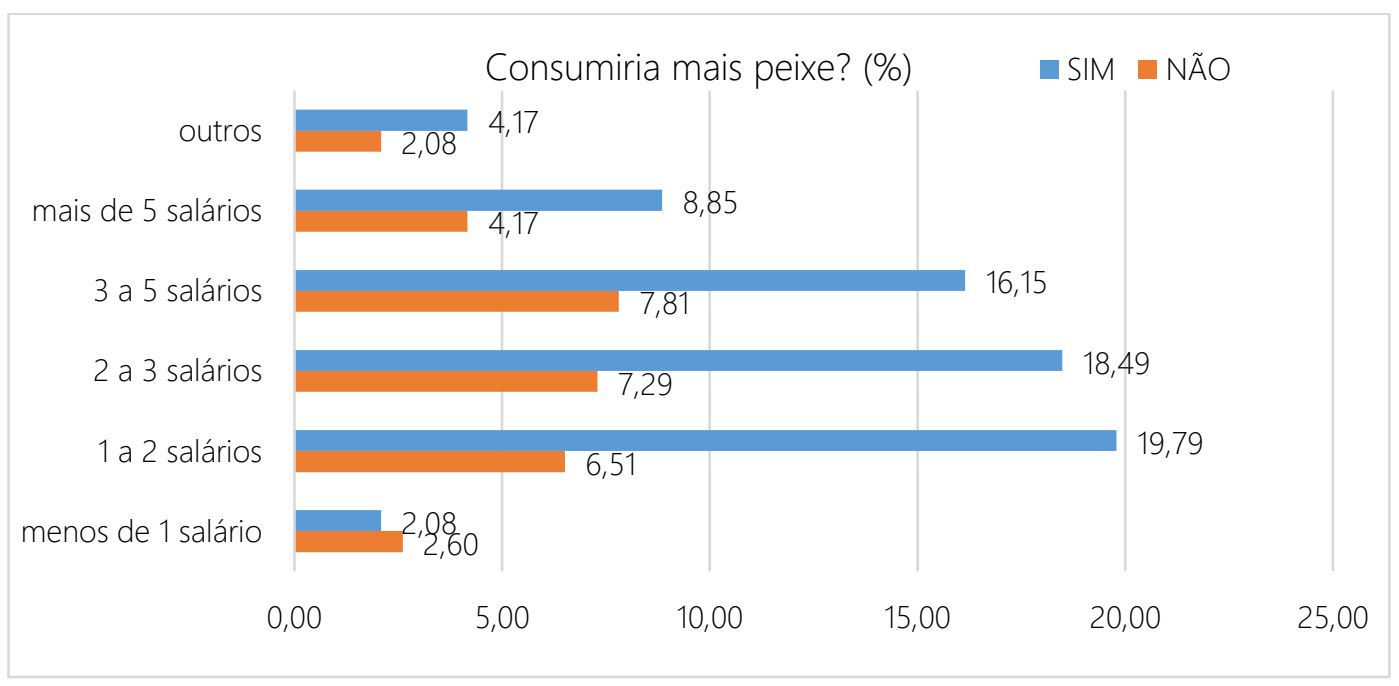

Figura 2. Quantidade em quilogramas $(\mathrm{kg})$ do consumo de peixe, pela frequência em que ocorre.

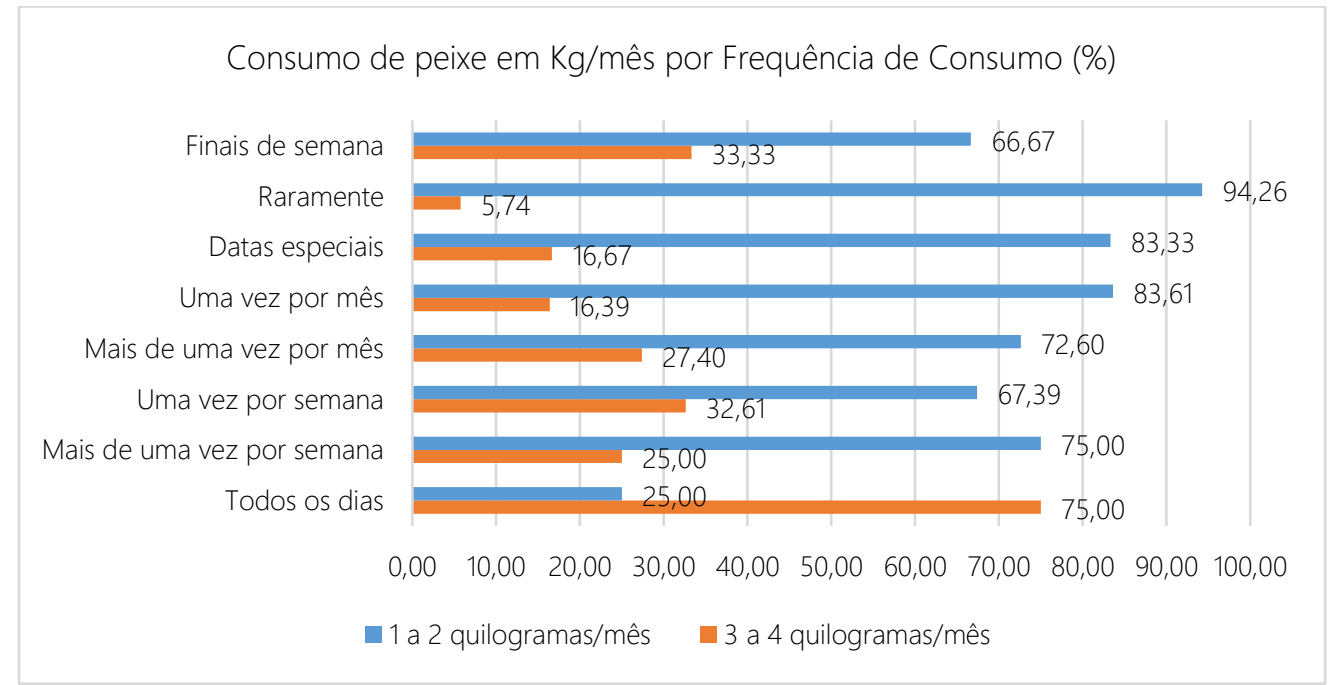

Os motivos que levam ao consumo de peixe, são sabor, carne saudável /valor nutricional e variação de cardápio, representando respectivamente, 29,96\%, 19,71\% e 14,40\% (Figura 3).

Muitos dos consumidores alegam adicionar peixe em sua dieta por ser 
uma carne de alta digestibilidade e ainda ter sabor diferenciado entre as espécies de peixes consumidas, o que é influenciado pelo hábito alimentar de cada espécie. Silveira et al. (2012), também verificaram que os dois fatores que mais levam ao consumo do pescado no município de Rio Grande, são o gosto pelo sabor da carne
(18,48\%) e o benefício a saúde /importância nutricional (17,52\%) que o consumo da carne de pescado representa.

Os motivos que levam ao não consumo de peixe são preço elevado (23, 51\%), preferência por outras carnes (21,19\%) e presença de espinhas (19,85\%) (Figura 4).

Figura 3. Motivos que levam ao consumo de peixe.

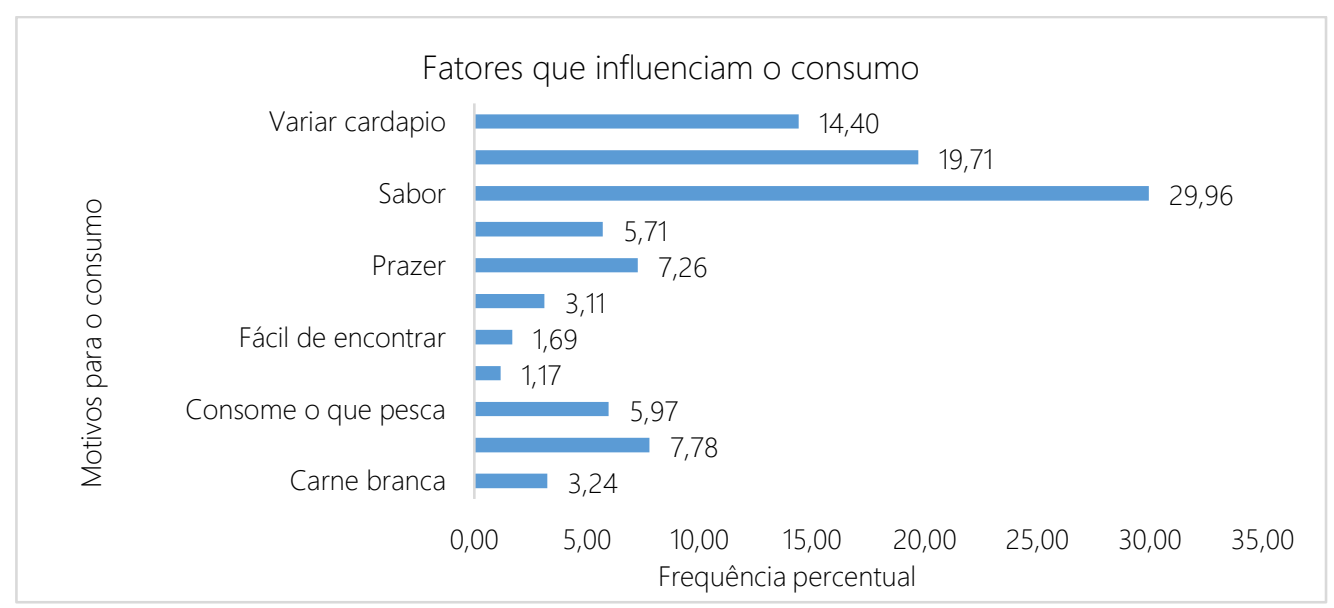

Figura 4 - Motivos que levam o consumidor a não consumir peixe.

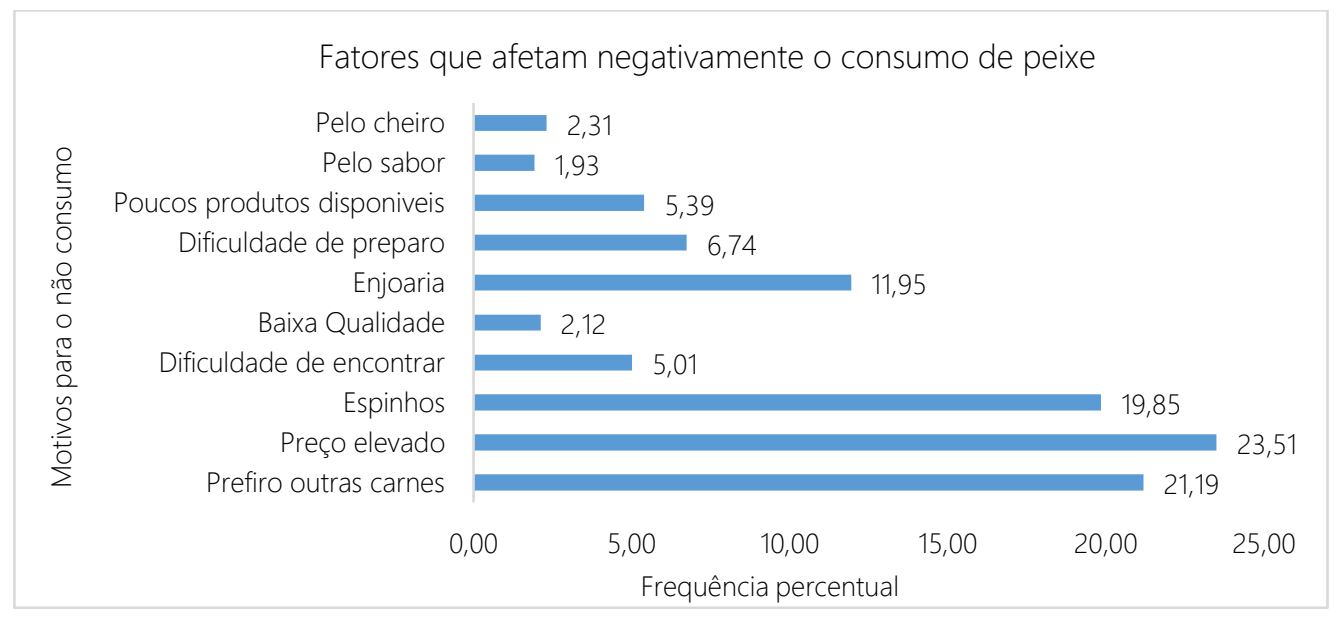


O alto preço ocorre porque a cadeia produtiva do peixe apresenta custo elevado, diferentemente do que acontece na produção de carne bovina e aves, as duas carnes mais consumidas no Brasil.

A preferência por outras carnes e presença de espinhas estão diretamente ligados a dificuldade que os indivíduos encontram em comer a carne de peixe. Dependendo da espécie a ser consumida apresentam baixa ou alta quantidade de espinhas na carne, mas é um fator que pode ser contornado com o processamento do pescado através de cortes especiais, que atenuam a presença de espinhos, mas que devido ao preço elevado dos produtos processados e a baixa oferta no mercado tornam o consumo ainda baixo.

Quanto aos fatores importantes que influenciam nas escolhas e decisão na aquisição do peixe destacam-se principalmente a aparência (17,40\%), a qualidade dos produtos $(17,00 \%)$ e o preço (12,11\%), conforme mostra a Figura 6. Soares e Belo (2015), verificaram que os atributos que mais influenciam na escolha e decisão dos consumidores de peixe do município de Porto Velho, Rondônia, são aparência, cheiro e validade, fatores esses que estão relacionados a qualidade e condições dos locais de venda.

Figura 5. Fatores que influenciam na decisão de aquisição de pescado.

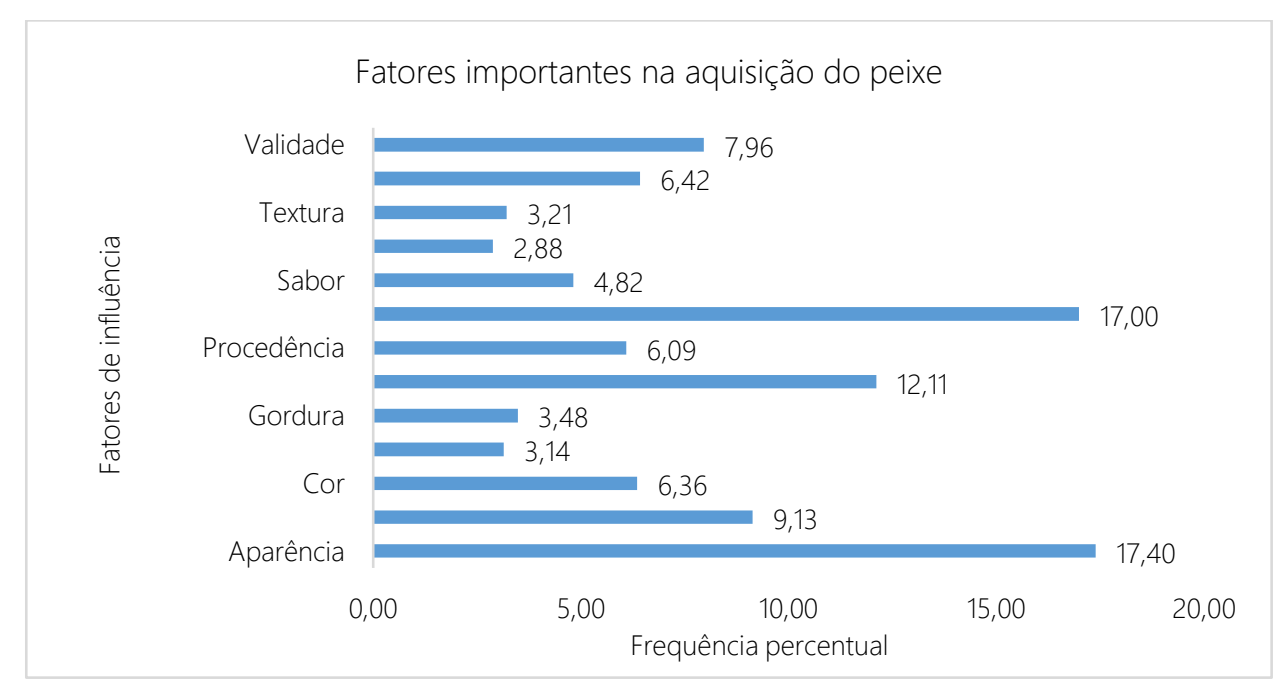


Com relação ao preparo do peixe, 42\% o consideram de fácil preparo, $34 \%$ difícil e 24\% igual de outras carnes, conforme mostra Figura 6. No mercado hoje é possível encontrar cortes especiais diversos e produtos processados o que torna mais prático o preparo da carne de peixe, como por exemplo, peixes defumados, précozidos, fish cake (empanados), pastas, entre outros produtos. Araújo et al. (2015), observaram que 68,27\% dos consumidores de peixe da feira de Porto Real do Colégio em Alagoas, acham fácil o preparo do peixe, 15,38\% difícil e 16,35\% igual as outras carnes.

Figura 6. Preparo do peixe e o consumidor.

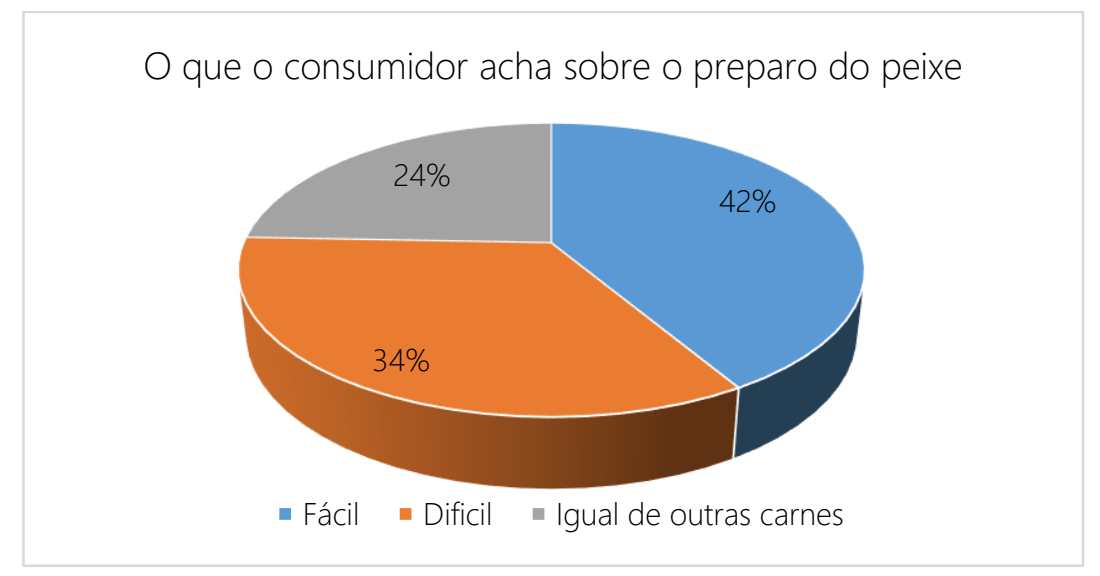

O consumidor de peixe de Sinop prefere comprar peixe no supermercado (40,55\%), e consumir na sua própria residência (40,19\%), conforme mostram os gráficos 6 e 7.0 trabalho de Tavares et al. (2013), em Belo Horizonte, Minas Gerais mostra que assim como ocorre na cidade de
Sinop, os consumidores preferem comprar pescado em supermercados sendo que a maioria consome o produto na residência. Esses resultados são diferentes aos observados em cidades localizadas às margens de grandes rios e/ou mar. 
Figura 7. Locais onde o consumidor de Sinop compra o peixe.

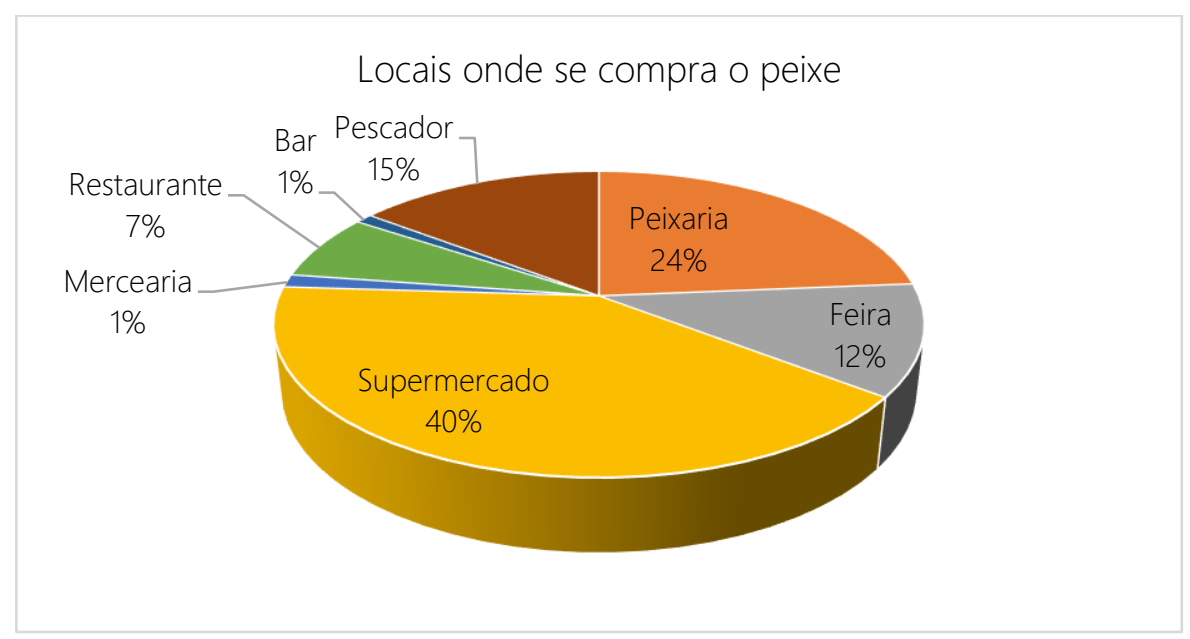

Figura 8. Locais onde os consumidores de peixe de Sinop consomem peixe.

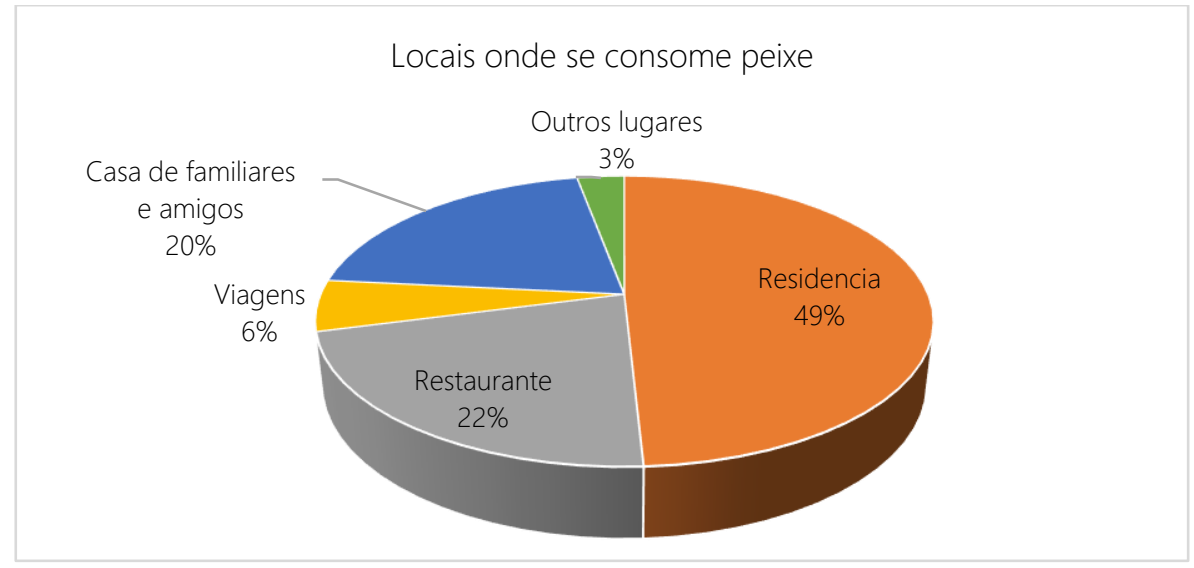

A comercialização de peixe em cidades a beira de rios, no geral, ocorre em feiras livres ou diretamente do pescador. $\bigcirc$ estudo de Costa et al. (2013), no município de Parintins, localizado as margens do rio Amazonas, indicou que as feiras são responsáveis pela comercialização de mais de 90\% do peixe daquele município, além do preço ser mais em conta.

A cidade litorânea de Coruripe, Alagoas onde os consumidores de pescado adquirem peixe em feiras (79,89\%), destaca-se como local de preferência de consumo a própria residência dos indivíduos (96,03\%), 
segundo estudo realizado por Santos et al. (2015).

Ao questionar o consumidor de peixe de Sinop sobre primeira e segunda ocasiões em que prefere realizar o consumo, as respostas obtidas mostraram que a maioria destes preferem consumir nos finais de semana (18,04\%), durante as refeições cotidianas $(13,79 \%)$ e em outras ocasiões (9,28\%), e não possuem uma segunda opção para ocasião de preferência, conforme demostrado na Figura 9.

Apesar desses resultados, eles não indicam que o consumidor realize frequentemente $\mathrm{O}$ consumo nessas ocasiões. A preferência por consumir aos finais de semana pode ser uma resposta ao alto preço, e por assim ser, se torna um produto pouco presente na mesa do consumidor.

A preferência por consumir em refeições cotidianas pode ser um indicativo da preocupação do consumidor por uma alimentação com maior valor nutricional e com menores riscos à saúde. Araújo et al. (2015), ao fazerem essa mesma pergunta verificaram que $60,19 \%$ dos consumidores de Porto Real do Colégio preferem consumir em refeições cotidianas (resposta para primeira ocasião), e 64,70\% em datas especiais (resposta para segunda ocasião).

Figura 9. Ocasiões em que o consumidor residente em Sinop prefere consumir peixe.

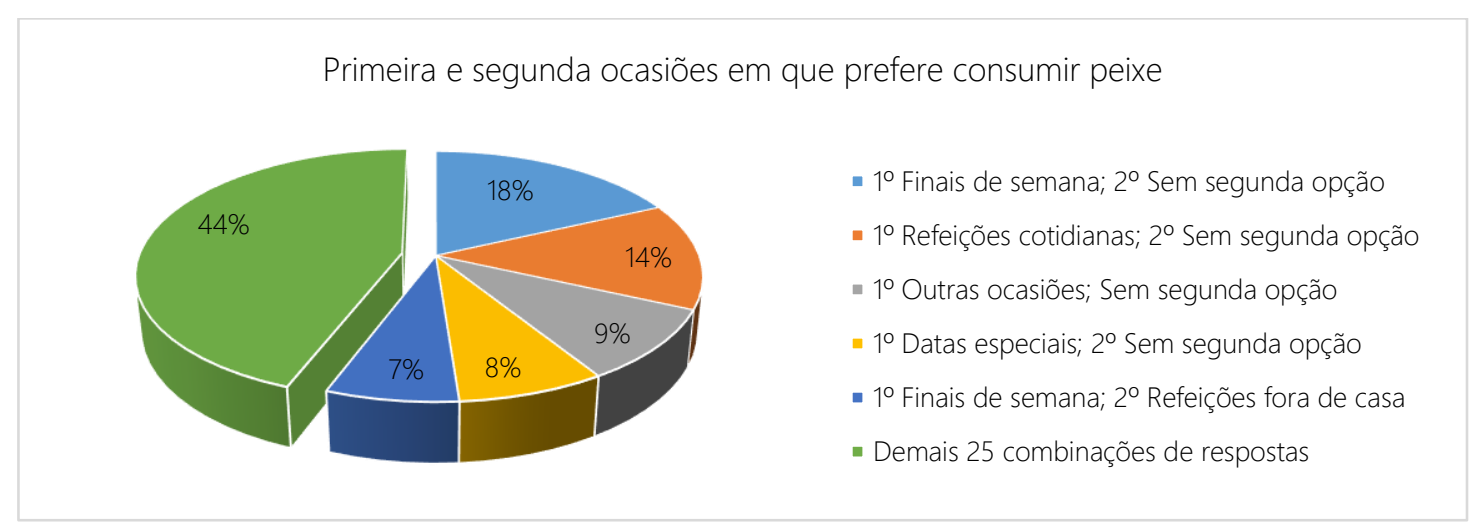


No Brasil a tendência por consumir pescado em datas especiais no Brasil de forma geral é influenciada pelas tradições religiosas. $\bigcirc$ povo brasileiro tem o hábito de aumentar o consumo em períodos e datas que marcam algum momento simbólico na vida religiosa, como é o caso da quaresma e semana santa, onde o consumo de carnes vermelhas é substituído pelo consumo de pescado, especialmente do peixe (BARROS et al., 2011).

Ao verificar a preferência do consumidor de Sinop quanto ao tipo de ambiente e produção de origem do peixe, observou-se que a preferência por peixes marinhos foi de apenas 4,15\%, talvez isso se deva à distância que o estado se encontra da região litorânea do país.

Já a preferência por peixes de água doce foi de $43,52 \%$, isso se deve ao fato do município estar localizado em um dos estados com maior produção destes, e com maior volume de água doce do mundo.

Quanto a preferência de peixe por locais de produção e extração, 81,25\% dos respondentes afirmaram preferir peixes advindos de rio. Segundo a pesquisa uma pequena parcela do consumidor de peixe de Sinop, diz não ter consumido peixe cultivado (16\%), dos entrevistados que já consumiram peixe de cultivo 62\% afirma notar diferença no sabor do peixe cultivado para o advindo de extrativismo (Tabela 2).

Ao questionar esse consumidor sobre agregação de valor, 58,97\% afirmaram que pagariam mais por cortes especiais, e segundo a Tabela 2 em torno de 70,76\%, dos consumidores, pagariam mais por peixe produzido de forma responsável no município.

No estudo realizado no município de Porto Real do Colégio, Alagoas, Araújo et al. (2015), observaram que 53,85\% daqueles consumidores não pagariam mais por cortes especiais e apenas 49,04\% pagariam mais por peixe produzido de forma responsável naquele município. Embora essa reposta reflita uma característica do consumidor, há no mercado diferentes tipos de cortes especiais para pescados, porém o preço é mais elevado se comparado ao peixe inteiro. 
Tabela 2. Resposta de consumidores sobre consumo de peixe cultivado, diferença que peixe cultivado e extrativismo, e se pagaria mais por uma produção responsável, dados em porcentagem (\%) $(n=434)$.

\begin{tabular}{|c|c|}
\hline \multicolumn{2}{|c|}{ Já comeu peixe cultivado? } \\
\hline $\begin{array}{l}\text { SIM } \\
\text { NÃO }\end{array}$ & $\begin{array}{l}84 \% \\
16 \%\end{array}$ \\
\hline \multicolumn{2}{|c|}{ Nota diferença entre o peixe cultivado e extrativismo? } \\
\hline $\begin{array}{l}\text { SIM } \\
\text { NÃO }\end{array}$ & $\begin{array}{l}62 \% \\
38 \% \\
\end{array}$ \\
\hline \multicolumn{2}{|c|}{ Pagaria mais por uma produção responsável no município? } \\
\hline $\begin{array}{l}\text { SIM } \\
\text { NÃO }\end{array}$ & $\begin{array}{l}70,76 \% \\
29,24 \%\end{array}$ \\
\hline
\end{tabular}

É importante ressaltar que existe um mito entre os consumidores de pescado em relação ao peixe cultivado, pois acreditam que o peixe cultivado tem gosto de barro ("off flavor"). Outros consumidores ainda afirmam que peixe de cultivo quando comparado aos de vida livre apresentam o sabor da carne diferente.

Sobre a presença ou não de escamas e espécies de peixes preferidas, 44,99\% responderam não ter preferência e consomem tanto de escama como de pele. Não houve diferença significativa pelo consumo de peixe de escama ou pele, de acordo com o sexo do consumidor, tanto homens (18,94\%) como mulheres $(26,04 \%)$ responderam gostar de ambos os peixes.

Alguns estados como Pará, Amazonas, tem esse consumo influenciado por alguns tabus, como a "reima" que ocasiona no menor consumo de peixe de pele ou "liso" dentro de determinados grupos de indivíduos ou épocas do ano (MURRIETA, 1998).

As espécies preferidas em Sinop conforme Figura 10, foram a matrinxã (Brycon falcatus) com 16,94\%, tambaqui (Colossoma macropomum) com 15,88\% (peixes com grande quatidade de espinhas intra musculares ou espinhas em "Y") e pintado da amazônia (Pseudoplatystoma reticulatum $\times$ Leiarius marmoratus) com 13,57\% (que não 
possui espinhas intra musculares ou $\left.e m^{\prime \prime} Y^{\prime \prime}\right)$. Estas espécies, segundo dados do MPA (2011), estão entre as mais cultivadas no estado de Mato Grosso. O estudo realizado por Leandro et al. (2015), no município de Santarém, Pará, revelou que naquele município as espécies preferidas são tambaqui (Colossoma macropomum) com 16,1\%, seguido do tucunaré (Cichla spp.) com 10,7\% e pirarucu (Arapaima gigas) com $10,5 \%$.

O consumidor de peixe de Sinop, tem preferência por adquirir peixe nas seguintes formas: inteiro fresco (23,28\%), filé fresco (17,57\%) e filé congelado (11,57\%), conforme a Figura 11. Esses resultados mostram que há uma maior preferência pelos produtos frescos.

Figura 10. Espécies de peixe preferidas pelo consumidor.

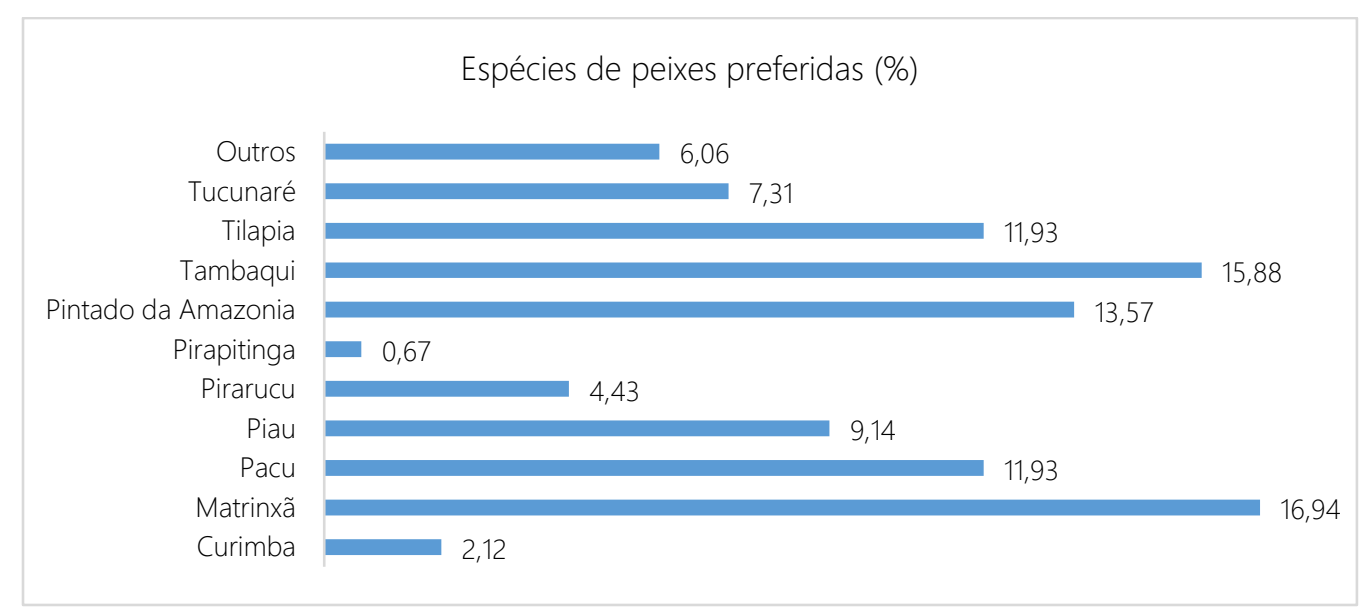

Figura 11. Formas de preferência para aquisição de peixe.

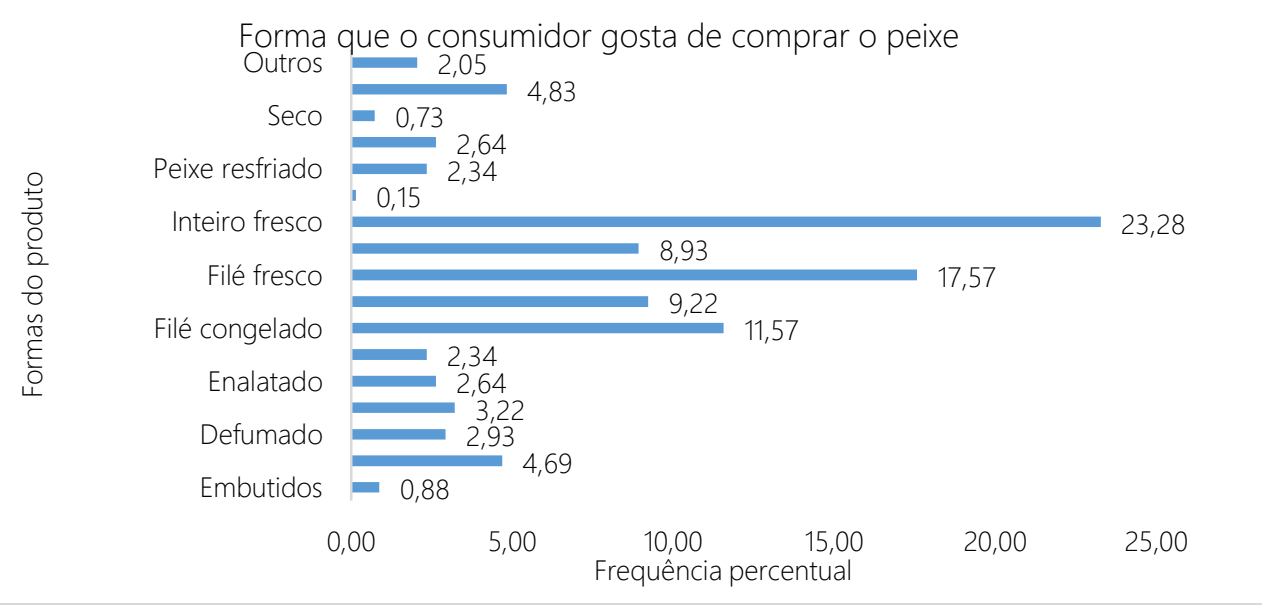


No trabalho de Leandro et al. (2015), em Santarém, Pará, o frescor do peixe $(32,3 \%)$ foi o fator que mais afetou no consumo, perdendo apenas para a preferência por peixe "tratado" (39,4\%), ou seja, peixes sem vísceras, escamas e ticado (para quebrar espinhas).

As formas de preparo preferidas pelo consumidor de peixe em Sinop são frito (32\%), assado (27\%), (Figura
12), o que corrobora com dados de Tavares et al. (2013), onde a preferência dos consumidores de pescado do município de Belo Horizonte, Minas Gerais foi frito (44,7\%) e assado (23\%). Esse fato pode estar relacionado à praticidade no preparo do peixe assado, frito ou grelhado quando comparado a outras formas de preparo.

Figura 12. Formas de preparo do peixe preferidas pelo consumidor.

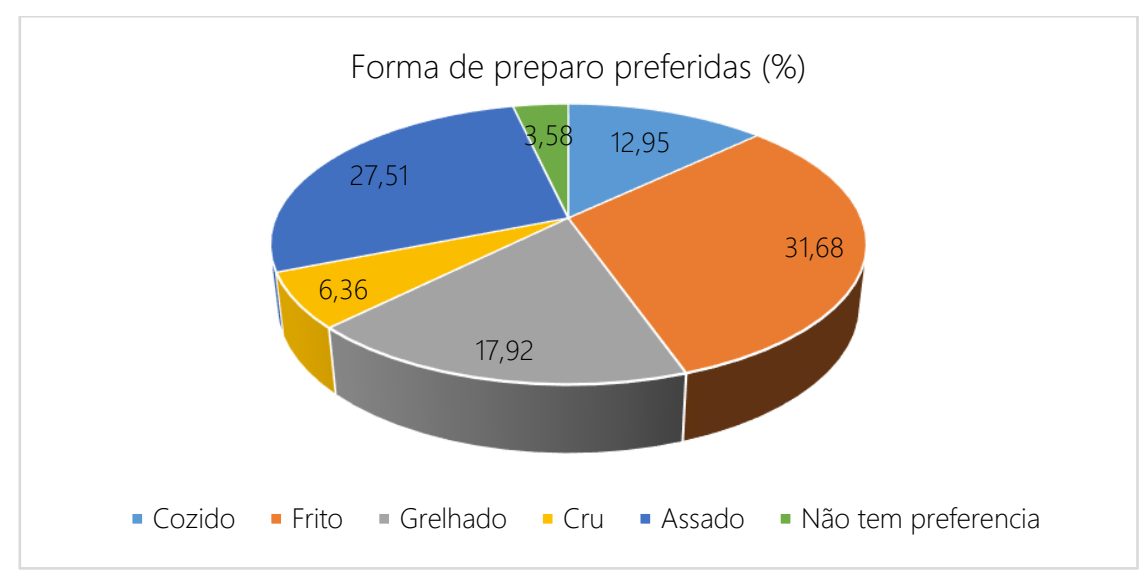

Com relação ao preço que o indicados por indivíduos com renda consumidor acha justo para o menor e os mais altos por aqueles com quilograma do peixe verificou-se que a poder aquisitivo mais elevado. Isso média indicada pelos entrevistados foi mostra que a renda familiar exerce de $R \$ 14,00 / \mathrm{Kg}$ de peixe, e quando forte influência sobre o consumo de observadas por classe de renda familiar peixe, assim como ocorre com outros essa média variou de $R \$ 12,00$ a $R \$ \quad$ produtos.

17,50. Os menores valores foram 
Araújo et al. (2015), observaram que $45,10 \%$ dos consumidores de peixe de Porto Real do Colégio, Alagoas consideram o valor de $R \$ 10,00$, e $16,67 \%$ o valor de $R \$ 8,00$ como justo para o quilograma de peixe. Uma diferença considerável quando comparado aos dados obtidos em Sinop, essa diferença pode ser devido a questões geográfica e socioeconômicas já que se tratam de cidades localizadas em estados diferentes.

A diferença quanto ao custo de vida nos diferentes municípios influencia no poder aquisitivo do consumidor, e consequentemente no valor que consideram justo para os produtos que fazem aquisição. Mesmo que a maioria dos consumidores não achem justo o preço do peixe, 34,30\% sugerem a redução do preço (Figura13).

O preço não é o único fator limitante para o consumo de peixe. Observa-se que segundo sugerido pelos consumidores é importante que se melhore a qualidade do pescado vendido, aumente o número de locais de comercialização e melhore higiene dos estabelecimentos.

Figura 13. Sugestão do consumidor para o aumento do consumo de peixe.

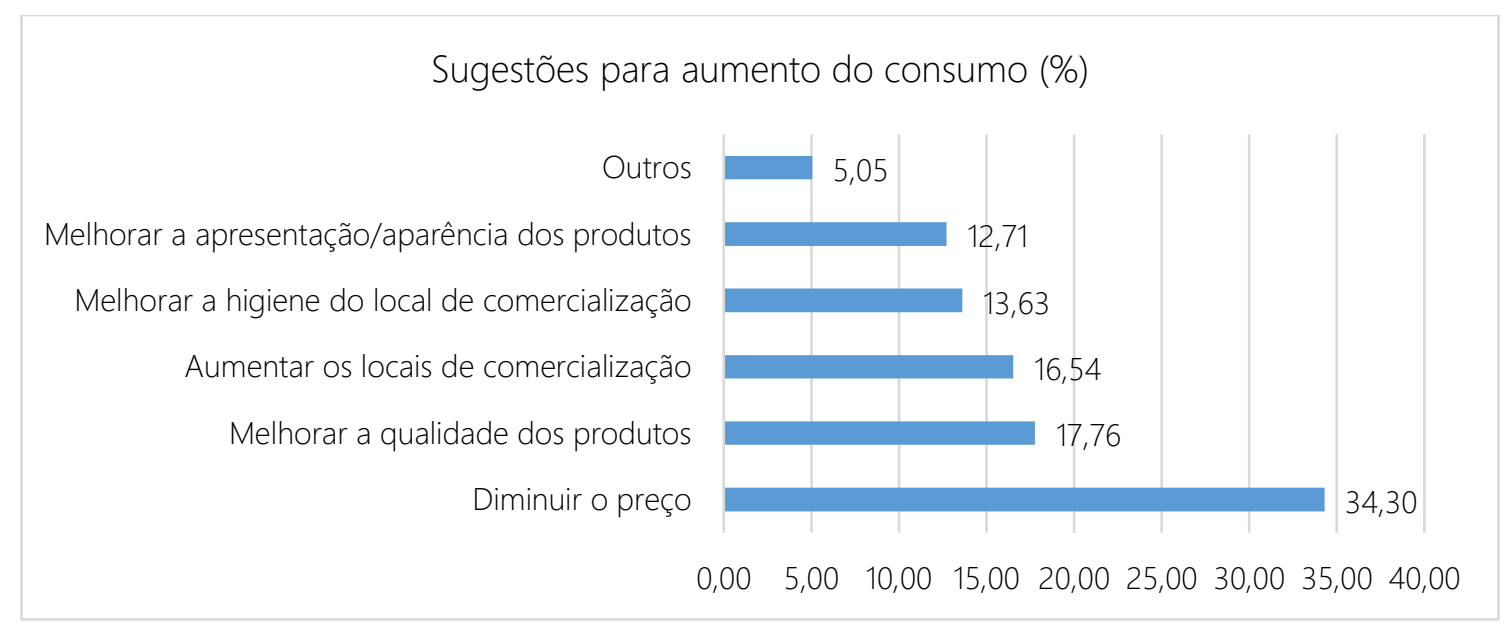


Este estudo buscou reconhecer as necessidades do mercado de peixes no município de Sinop, além das exigências do consumidor pois como relatado por Mccarthy e Perreault (1997), o consumidor é o marcador do mercado de um determinado produto.

\section{CONCLUSÕES}

O perfil de consumo de peixe em Sinop é influenciado diretamente pela renda familiar dos consumidores, onde quantidade e frequência do consumo de peixe é maior entre indivíduos de classes com maior poder aquisitivo. A idade, o sexo, o estado de origem e escolaridade não exercem influência direta no consumo de peixe no município. Os fatores que facilitam o consumo de peixe são: renda, processamento do produto, qualidade do produto e dos locais de venda, valor nutricional da carne e a presença de produtos frescos no mercado. Apesar de indicar espinhos como um dos fatores limitantes as espécies preferidas são a matrinxã e o tambaqui, seguidos do pintado da Amazônia que possui menor quantidade de espinhos, além disso, tem preferência por formas práticas de preparo, como assado e frito. Outro fator detectado neste estudo é de que não há a cultura de consumir peixe em grandes quantidades devido a cidade de Sinop ter sido colonizada por sulistas.

O mercado é quem define os caminhos e decisões a serem tomados em uma produção, com isso faz-se necessário que produtores e comerciantes investiguem e estejam atentos as exigências do consumidor final de peixe no município de Sinop, para que se tomem medidas que atendam às necessidades do consumidor, elevando assim a movimentação da cadeia produtiva e comercial do peixe no município de Sinop.

\section{REFERÊNCIAS}

ARAÚJO, D. M.; LINS, J. L. F.; TAVARES, A. S.; SILVA, J.; SILVA, V. M. D.; BORDINHON, A. M. Aspectos de Aquisição e Consumo de peixes na Feira Livre de Porto Real do Colégio Alagoas. Boletim do Instituto de Pesca, São Paulo, v. 41, n. 4, p. 961-973, 2015. 
BARROS, G. S.; MENESES, J. N. C.; SILVA, J. A. Representações sociais do consumo de carne em Belo Horizonte. Physis Revista de Saúde Coletiva, Rio de Janeiro, v. 22, n. 1, p. 365-383, 2011.

BRABO, M. F.; PEREIRA, L. F. S.; SANTANA, J. V. M.; CAMPELO, D. A. V.; VERAS, G. C. Cenário atual da produção de pescado no mundo, no Brasil e no estado do Pará: ênfase na aquicultura. Acta of Fisheries and Aquatic Resources, v. 4, n. 2, p.50-58, 2016.

COSTA, T. V.; SILVA, R. R. S.; SOUZA, J. L.; BATALHA, O. S.; HOSHIBA, M. A. Aspectos do consumo e comércio de pescado em Parintins. Boletim do Instituto de Pesca, São Paulo, v. 39, n. 1, p. $63-75,2013$.

ESTIMA, C.C. P.; PHILIPPI, S. T.; ALVARENGA, M. S. Fatores determinantes de consumo alimentar: por que os indivíduos comem o que comem? Revista brasileira de nutrição clínica, Porto Alegre, v. 24, n. 4, p. 263 268, 2009.

FAMATO - FEDERAÇÃO DA AGRICULTURA E PECUÁRIA DO ESTADO DE MATO GROSSO. Diagnóstico da Piscicultura em Mato Grosso. - Instituto Mato-Grossense de Economia Agropecuária (Imea) Cuiabá, 2014. Disponível em: <http://imea.com.br/site/upload/pdf/a rquivos/P221_Diagnostico_da_Piscicult_ ura_Versao_Final_com_capa.pdf> Acesso em: 21 set. 2016.
FAO - FOOD AND AGRICULTURE ORGANIZATION - FAO. The State of World Fisheries and Aquaculture. FAO Fisheries Departament. Rome: Italy, 2014. Disponível em: < http://www.fao.org/3/a-i3720e.pdf> Acesso em: 21 set. 2016.

IBGE - INSTITUTO BRASILEIRO DE GEOGRAFIA E ESTATISTICA. Mato Grosso, Sinop, Infográficos: histórico. Brasil, 2011. Disponível em: <http://ibge.gov.br/cidadesat/painel/h istorico.php?lang $=\&$ codmun $=510790 \&$ search =mato-

grosso|sinop|infograficos:-historico> Acesso em: 21 set. 2016.

IBGE - INSTITUTO BRASILEIRO DE GEOGRAFIA E ESTATISTICA. Mato Grosso, Sinop, Infográficos: Dados gerais do município. Brasil, 2013. Disponível em:<http://ibge.gov.br/cidadesat/pain el/painel.php?lang $=$ \&codmun $=510790$ \&search=matogrosso|sinop|infograficos:-dadosgerais-do-municipio> Acesso em: 21 set. 2016.

IBGE. INSTITUTO BRASILEIRO DE GEOGRAFIA E ESTATístICA. Município, Sinop Mato Grosso. Brasil, 2015. Disponível em:< http://cidades.ibge.gov.br/painel/histo rico.php?codmun $=510790>$ Acesso em: 21 set. 2016.

LEANDRO, S. V.; OTANI, F. S.; SOUSA, J. E. M.; PAULA, T. C. P. Perfil de Consumo e Consumidor de Pescado no município de Santarém, Pará. In: CONGRESSO BRASILEIRO DE 
ZOOTECNIA, 25., 2015, Fortaleza. Anais... Dimensões Tecnológicas e Sociais da Zootecnia. Fortaleza - CE, 2015.

MAIA, H.M.S. Hábitos e determinantes do consumo de pescado em profissionais ligados à saúde. Trabalho de Investigação. Faculdade de Ciências da Nutrição e Alimentação da Universidade do Porto, Porto, 2012.

MCCARTHY, E. J.; PERREAULT, W. D. Marketing Essencial: Uma abordagem gerencial e global. São Paulo: Atlas, 1997. 397 p.

MPA - MINISTÉRIO DA PESCA E AQUICULTURA. Boletim Estatístico da Pesca e Aquicultura. Secretaria de Monitoramento e Controle do MPA. Brasil, 2011. Disponível em: <http://www.icmbio.gov.br/cepsul/images /stories/biblioteca/download/estatistica/es t_2011_bol_bra.pdf> Acesso em: 20 out. 2017.

MPA - MINISTÉRIO DA PESCA E AQUICULTURA. Plano de Desenvolvimento da Aquicultura Brasileira - 2015/2020. Brasília, DF, 2015.

MURRIETA, R. S. S. O dilema do papachibé: consumo alimentar, nutrição e práticas de intervenção na Ilha de Ituqui, baixo Amazonas, Pará. Revista de Antropologia, São Paulo, v.41, n.1, p. 97-150,1998.

ONU. Organização das Nações Unidas. (2013). População mundial deve atingir 9,6 bilhões em 2050, diz novo relatório da ONU. Disponível em: https://nacoesunidas.org/populacaomundial-deve-atingir-96-bilhoes-em2050-diz-novo-relatorio-da-onu/ > Acesso em: 23 abr. 2017.

PINHEIRO, A.; LENZI, A.; SEGANFREDO, A.; GONÇALVES, B.; MARTINS, D.; CARDOSO, D.; FURTADO; LIZ, F.; UMPIERRES, $F_{\text {; }}$ CARDOZO, F.; SANTOS, K.; LAPS, L.; ZONTA, L.; BRUNING, M. T.; BOING, M.; KAFRUNI, S.; MARTIN, W. 10 Anuário Brasileiro da Pesca e Aquicultura. Associação Cultural E Educacional do Brasil - ACEB. 15 de janeiro de 2014.

ROMANCINI, S. R. Novas Territorialidades nas Cidades Matogrossenses. Editora da Universidade Federal de Mato Grosso. Cuiabá: EdUFMT, 2009.

RYAN, T. Estatística Moderna para Engenharia. São Paulo: Elsevier, 2012. p. 04.

SANTOS, E. L.; SOARES, E. C.; SILVA, T. J.; JANUÁRIO, I. C. M.; GARCIA, P. H. M.; MOURA, S. C. S. PERFIL DO CONSUMO DE PESCADOS NA CIDADE DE CORURIPE, ALAGOAS. Acta Veterinaria Brasilica, v.9, n.2, p.153-159, 2015.

SEBRAE - SERVIÇO BRASILEIRO DE APIO ÀS MICRO E PEQUENAS EMPRESAS. Aquicultura no Brasil. 2015. (Série Estudos Mercadológicos). Disponível em: < http://www.bibliotecas.sebrae.com.br /chronus/ARQUIVOS_CHRONUS/bds/ bds.nsf/4b14e85d5844cc99cb32040a4 
980779f/\$File/5403.pdf> Acesso em: 17 abr. 2017.

SILVEIRA， L.S.; ABDALLAH， P.R.; HELLEBRANDT, L.; BARBOSA, M.N.; FEIJÓ, F.T. Análise socioeconômica do perfil dos consumidores de pescado no município de Rio Grande. SINERGIA, Rio Grande, v. 16, n. 1, p. 9-19, 2012.

SOARES, L.; BELO, M. A. A. consumo de pescado no município de porto velhoro. Enciclopédia Biosfera, Centro Científico Conhecer - Goiânia, v.11, n.21, p.3059, 2015.

SONODA, D. Y.; SHIROTA, R. Consumo de pescado no Brasil fica abaixo da média internacional. Mercado e Consumo. Visão Agrícola, n. 11, jul dez, 2012.

TAVARES, G. C.; AQUINO, R. M. A.; PALHARES, M. M.; SANTOS, R. R. D.; BONFIM, L. M.; TEIXEIRA, L. V. Perfil do consumo de pescado na cidade de belo horizonte, MG. B. Indústria animal, Nova Odessa, v. 70, n. 3, p.2, 2013.

TEIXEIRA, L. A colonização no norte de Mato Grosso: o exemplo da gleba celeste. 2006. 117 f. Dissertação (Mestrado) - Universidade Estadual Paulista, Faculdade de Ciências e Tecnologia, 2006.

VASCONCELLOS, J. P. Determinantes do consumo de pescado na população que frequenta as feiras livres do município de Santo André, SP. 2010. 102 f. Dissertação (Mestrado em Ciências) - Universidade de São Paulo,
Faculdade de Medicina Veterinária e Zootecnia, São Paulo, 2010. 